\title{
Alcohol Consumption, Depression, Insomnia and Colorectal Cancer Screening: Racial Differences
}

\author{
Daniel Owusu ; Megan Quinn '; Ke Sheng Wang ${ }^{1, *}$ \\ ${ }^{1}$ Department of Biostatistics and Epidemiology, College of Public Health, East Tennessee State University, Johnson City, USA \\ ${ }^{*}$ Corresponding author: Ke Sheng Wang, Department of Biostatistics and Epidemiology, College of Public Health, East Tennessee State University, Johnson City, USA. Tel:+1-4234394481, \\ Fax:+1-4234394606, E-mail: wangk@etsu.edu \\ Received: September 8, 2014; Accepted: October 24, 2014
}

\begin{abstract}
Background: Mortality from colorectal cancer (CRC) can be reduced drastically by early detection and early treatment. However, uptake of CRC screening is relatively low, about $50 \%$ for those whom the test is highly recommended.

Objectives: We examined the influence of and racial differences in depression, insomnia, alcohol use, and tobacco use on CRC screening uptake in the US.

Patients and Methods: Analysis of the 2012 National Health Information Survey data was conducted. Both weighted univariate and multiple logistic regression analyses were performed in SAS to estimate the odds ratios (ORs) and their 95\% confidence intervals (CIs). A total of 21511 participants were included in the analysis.

Results: Prevalence of CRC screening in the participants was 19\%. Adjusting for all factors, insomnia $(\mathrm{OR}=1.18,95 \% \mathrm{CI}=1.06-1.32)$, moderate alcohol drinking $(\mathrm{OR}=1.16,95 \% \mathrm{CI}=1.01-1.30)$, past smoking $(\mathrm{OR}=1.17,95 \% \mathrm{CI}=1.04-1.32)$, depression $(\mathrm{OR}=1.37,95 \% \mathrm{CI}=1.18-1.58)$, African American (AA) race, and cancer history were positively associated with CRC screening. Females and Single were inversely associated with CRC screening prevalence. In stratified analysis by races (White and AA), depression was associated with CRC screening in both races. Marital status, smoking, cancer history and insomnia were associated with CRC screening in Whites only; while alcohol use was associated with CRC screening in AAs only.

Conclusions: We have found significant associations between lifestyle factors (alcohol consumption and smoking) and mental health problems (depression and insomnia) and CRC screening uptake. To improve overall CRC screening uptake in the US, it is important to consider racial differences in predictors and tailor appropriate interventions to each racial/ethnic group.
\end{abstract}

Keywords: Colon Cancer; Screening; Alcohol Consumption; Depression; Insomnia

\section{Background}

Colorectal cancer (CRC) remains the second leading cause of cancer deaths in the United States (US) (1), despite the high survival rate from early treatment (2). It is estimated that 136830 new cases of colorectal cancer will be recorded in 2014 in the US and 50310 of these cases will die from the disease (3). Cancer of the colon and rectum affects both males and females equally, and the risk increases with age $(3,4)$. Mortality from CRC can be reduced drastically by early detection and early treatment. The survival rate for colorectal cancer is very low at late diagnosis of the disease. Five-year survival rates as high as about $90 \%$ have been reported for tumors detected and removed before extension (2). Evidence also indicates a reduction in the survival rate to about $70 \%$ for tumors which have already extended, and as low as $13 \%$ when metastasis has already occurred (2). Decline in CRC mortality rates in the US has been attributed to early detection and surgical removal of the tumor before metastasis (5). Early detection and early treatment are possible due to the availability of effective and relatively inexpensive CRC screening tests (6). A clinical trial showed 33 and $43 \%$ reductions in incidence and mortality of CRC respectively as result of a single sigmoidoscopy screening of adults between 55 and 64 years (7). In the US, CRC screening is covered by most health plans and there is a published guideline for CRC screening (8). However, uptake of CRC screening is relatively low, and it is about $50 \%$ of those for whom the test is highly recommended (9-11). This calls for public health efforts to increase awareness, acceptance and uptake of CRC screening, especially for those with increased risk. Researching factors that promote CRC screening is therefore crucial for public health interventions. Reported predictors of CRC screening include age, educational level, income level, and health insurance status $(9,12)$. These predictors are similar to predictors for other screening programs, such as mammography. It therefore raises questions about the low uptake of CRC compared to screening programs for other cancers. This calls for more investigation into predictors of CRC screening uptake to inform policy and intervention planning. Several studies exist on the relationship between mental health and attitudes towards health programs. The link between depression, alcohol and tobacco

Copyright (C) 2015, Zahedan University of Medical Sciences. This is an open-access article distributed under the terms of the Creative Commons Attribution-NonCommercial 4.0 International License (http://creativecommons.org/licenses/by-nc/4.0/) which permits copy and redistribute the material just in noncommercial usages, provided the original work is properly cited. 
use; and screening uptake have also been investigated. However, studies have differed on their findings. A study investigated the influence of depression on other cancer screening among breast cancer survivors in Latino. An inverse association was observed between depression and CRC screening uptake (13). A recent survey in Washington State in the US identified depression as a significant barrier to cervical cancer screening uptake (14). This finding partly corroborated a previous observation made in Canada (15). However, Kaida and co-workers (15) observed that age played an important role in the relationship between depression and cervical cancer screening. In contrast, Kodl and co-workers observed a significant increase in CRC uptake among those with mental health diagnosis in a bivariate analysis (16). However, inverse association was observed when they controlled for timing of diagnosis and outpatient visits. This observation suggests that depression affects screening indirectly. In the United Kingdom, it was observed that lower depression indirectly increases uptake of CRC screening through a better self-rated health (17). These findings call for more investigation into the relationship between mental health and CRC screening to inform policy and intervention. Insomnia has been found to be common among cancer patients (18). However, to the best of our knowledge, the relationship between insomnia and CRC screening uptake has not yet been evaluated. Again, racial differences in the influence of depression on CRC screening have not yet been evaluated.

\section{Objectives}

We examined the influence of and racial differences in depression, insomnia, alcohol use, and tobacco use on CRC screening uptake in the USA.

\section{Patients and Methods}

\subsection{Data Source}

The National Health Interview Survey (NHIS) is a multipurpose health survey which is conducted by the National Center for Health Statistics (NCHS), Center for Disease Control and Prevention (CDC). It is a principal source of health information of the civilian noninstitutionalized household population of the US. The NHIS has been conducted continually since it began in 1957. Public-use data files are released annually and can be accessed from the internet. From each family in the NHIS, one adult aged 18 years or older is randomly selected to respond to sample adult core questionnaires. Details of the methods of this survey have been published elsewhere (19). The 2012 NHIS sample is the largest sample size since the current sampling strategy came into force in 2006. Analysis of 2012 data from the National Health Information survey (NHIS) was done to determine associations between depression, insomnia, alcohol use and tobacco use, and colorectal cancer screening in participants.
Table 1. Subjects Characteristics of the 2012 National Health Interview Survey $\mathrm{a}, \mathrm{b}, \mathrm{c}$

\begin{tabular}{|ccc|}
\hline Variable & $\begin{array}{c}\text { CRC Screening } \\
(\mathbf{n}=\mathbf{4 0 4 0})\end{array}$ & $\begin{array}{c}\text { Non-Screening } \\
(\mathbf{n}=\mathbf{1 7 4 7 1})\end{array}$ \\
\hline Gender & $2026(54)$ & $7516(46)$ \\
\hline Male & $2014(46)$ & $9955(54)$ \\
\hline Female & $182(6)$ & $2609(16)$ \\
\hline Age group,y & $2194(59)$ & $9340(57)$ \\
\hline $18-44$ & $1664(36)$ & $5522(27)$ \\
\hline $45-64$ & & $13015(80)$ \\
\hline$\geq 65$ & $2819(79)$ & $2469(10)$ \\
\hline Race & $800(13)$ & $547(3)$ \\
\hline White & $129(3$ & $1440(7)$ \\
\hline AA & $292(5)$ & \\
\hline Asian & & $8916(66)$ \\
\hline Other & $1431(26)$ & $6401(25)$ \\
\hline Marital status & $2205(70)$ & $2105(9)$ \\
\hline Married & $1447(24)$ & $4944(32)$ \\
\hline Divorced & $385(6)$ & $4379(36)$ \\
\hline Single & & \\
\hline Income, USD & & \\
\hline 0 - 34999 & & \\
\hline $35000-74999$ & $1198(33)$ & \\
\hline$\geq 75000$ & & \\
\hline Cancer & & \\
\hline
\end{tabular}

\section{Cancer his-}

tory

$\begin{array}{ccc}\text { No } & 3285(82) & 15406(88) \\ \text { Yes } & 753(18) & 2054(12)\end{array}$

\begin{tabular}{|ccc|}
\hline Alcohol use & & \\
\hline Never & $776(18)$ & $3897(21)$ \\
\hline Past & $888(21)$ & $3455(20)$ \\
\hline $\begin{array}{l}\text { Moderate } \\
\text { Smoking } \\
\text { status }\end{array}$ & $2151(61)$ & $9055(50)$ \\
\hline Never & & \\
\hline Current & $2063(51)$ & $9609(56)$ \\
\hline Past & $623(14)$ & $3135(17)$ \\
\hline Depress & $1348(35)$ & $4695(27)$ \\
\hline No & $3244(87)$ & $14609(89)$ \\
\hline Yes & $570(13)$ & $2082(11)$ \\
\hline Insomnia & & $13556(79)$ \\
\hline No & $3021(76)$ & $3912(21)$ \\
\hline Yes & $1018(24)$ & \\
\hline
\end{tabular}

\footnotetext{
a Abbreviations: AA, African American.

b Data Source: CDC/NCHS, National Health Interview Survey, 2012
}

c Data are presented as No. (\%). 
Owusu D et al.

\subsection{Measurements}

Information on depression, insomnia, alcohol use and tobacco use was self-reported. Participants were considered to have had a CRC screening (case) if they responded "yes" to the question "Test for colon cancer, past 12 months" (Table 1). Subjects who answered "no" to the question served as controls. Demographic variables collected and used in this analysis included age, classified as young (18 - 44 years), middle aged ( 45 - 64 years), and elderly (65 years or older); gender; race/ethnicity (White, African American (AA), Asian and other). Marital status was classified into married/living with partner; widowed/divorced/separated; and Single. Insomnia was determined by the question "Insomnia, past 12 months" (yes. no). Depression case was recorded from "yes" answer to the question "Ever had depression, past 12 months" (yes/no). Smoking status was classified as never smoked, current smoking, or past smoking. Alcohol consumption was classified as never, current light or moderate drinking, and past drinking. Income level was categorized into low income (0 - 34999 USD), middle income (35000 - 74999 USD) and high income ( $\geq 75000$ USD).

\subsection{Statistical Analysis}

Population proportions in cases and controls of independent variables and demographic factors were estimated by PROC SURVEYFREQ procedure in SAS. PROC SURVEYMEANS procedure was also used to estimate the overall prevalence of CRC screening; while SAS PROC SURVEYFREQ was used to estimate the prevalence in potential factors. Chi-square test was used to compare prevalence of CRC screening across groups. Odds ratios (ORs) and their 95\% confidence intervals (CIs) were estimated for each of the suspected predictors of CRC screening by PRC SURVEYLOGISTIC procedure. A multiple logistic regression was performed for all races combined and then stratified by race (white and AA). All the analyses were conducted with SAS statistical software, version 9.2 (SAS Institute, Cary, NC, USA).

\section{Results}

\subsection{Subjects Characteristics and Prevalence}

There were 21511 participants included in the analysis, comprising 9542 (44\%) males and 11966 (56\%) females. Table 1 shows detailed characteristics of the study participants. A higher percentage of males reported having CRC screening in the last 12 months (54\% vs. 46\%). Proportion of older adults was higher in cases than in controls (36\% vs. $27 \%$ ). African-American (AA) adults and married also formed higher proportions in cases than in controls (13\% vs. $10 \%, 70 \%$ vs. $66 \%$, respectively). A higher proportion of cases had higher income than controls ( $41 \%$ vs. $36 \%$ ). Table 2 illustrates the prevalence of CRC screening by demographic factors and other independent variables. The overall prevalence of CRC screening in the sample was $19 \%$. The prevalence of CRC screening in adults with cancer, depression and insomnia was significantly higher than those without the conditions (26\% vs.18\%; $21 \%$ vs. $18 \%$; and $21 \%$ vs.18\%, respectively). Prevalence of CRC screening was highest in past smokers compared to current smokers and never smokers (23\% vs. $16 \%$ vs. $18 \%$ ). Participants with past alcohol use recorded the highest prevalence of CRC screening compared to current and never alcohol users (20\% vs. $19 \%$ vs. $16 \%$ ).

\subsection{The Relationship Between all Potential Risk Factors and CRC Screening in all Races}

Results of both univariate and multiple logistic regression analyses of the association between CRC screening and all factors included in the model are shown in Table 3. There were significant associations between CRC screening and all factors examined in the unadjusted analysis $(\mathrm{P}<0.05)$. Adjusting for all other factors, cancer history ( $\mathrm{OR}=1.51,95 \% \mathrm{CI}=1.32-1.73$ ); moderate alcohol drinking $(\mathrm{OR}=1.16,95 \% \mathrm{CI}=1.01-1.30)$; past smoking $(\mathrm{OR}=1.17,95 \% \mathrm{CI}$ $=1.04$ - 1.32); depression $(\mathrm{OR}=1.37,95 \% \mathrm{CI}=1.18$ - 1.58); $\mathrm{AA}$ $\operatorname{race}(\mathrm{OR}=1.74,95 \% \mathrm{CI}=1.53-1.98)$ and insomnia $(\mathrm{OR}=1.18$, $95 \% \mathrm{CI}=1.06-1.32)$ were all positively associated with CRC screening. Females (OR $=0.73 ; 95 \% \mathrm{CI}=0.66-0.82)$ and Single $(\mathrm{OR}=0.78,95 \% \mathrm{CI}=0.66-0.91)$ were inversely associated with CRC screening prevalence. Compared to young adults (18 - 44 years), screening was significantly higher in middle-aged and the older adults $(\geq 65)(\mathrm{OR}=$ $2.91,95 \% \mathrm{CI}=2.35-3.62$ and $\mathrm{OR}=3.76,95 \% \mathrm{CI}=2.99-4.74$, respectively). Compared to low income earners (0 - 34999 USD), CRC screening was significantly higher in middle income (35000 - 74999 USD) and high income ( $\geq 75000)$ earners $(\mathrm{OR}=1.32,95 \% \mathrm{CI}=1.17-1.48$; and $\mathrm{OR}=1.50,95 \% \mathrm{CI}$ $=1.31-1.73$, respectively).

\subsection{Relationship Between CRC Screening and all Factors Stratified by Race (White and African American)}

Table 4 provides detailed results of multiple logistic regression analysis, stratified by race. Adjusting for all other factors, age, income and depression showed significant positive association with CRC screening in both Whites and AAs. In both races, females were less likely to screen for CRC. While the single were significantly less likely to receive $\mathrm{CRC}$ screening among Whites $(\mathrm{OR}=0.75,95 \% \mathrm{CI}=$ 0.61-0.92), marital status was not significantly associated with CRC screening among AA ( $\mathrm{P}>0.4)$. Cancer history was positively associated with CRC screening in Whites $(\mathrm{OR}=1.55,95 \% \mathrm{CI}=1.33-1.79)$ but not significant in AAs ( $\mathrm{P}$ $>0.1$. There was a $47 \%$ significant increase in CRC screening in past alcohol users among AAs (95\% CI $=1.06$ - 2.09) but alcohol use was not associated with CRC screening in Whites (P>0.1). In both races, CRC screening was slightly 
Owusu D et al.

but not significantly reduced in current smokers, however, past smoking was positively associated with CRC screening in Whites $(\mathrm{OR}=1.29,95 \% \mathrm{CI}=1.09-1.53)$ but not in AAs. History of insomnia also increased CRC screening in Whites $(\mathrm{OR}=1.17,95 \% \mathrm{CI}=1.03-1.34)$ but it was not significantly associated with CRC screening in AAs.

Table 2. CRC Prevalence of Demographic Characteristics (\%)

\begin{tabular}{|c|c|c|c|c|c|}
\hline Variable & Total, $\mathbf{N}$ & Cases, $\mathbf{N}$ & Prevalence, \% & 95\%CI & PValue \\
\hline Gender & & & & & $<0.0001$ \\
\hline Male & 9542 & 2026 & 21.2 & $20.2-22.3$ & \\
\hline Female & 11969 & 2014 & 16.5 & $15.62-17.4$ & \\
\hline Age group, y & & & & & $<0.0001$ \\
\hline $18-44$ & 2791 & 182 & 7.4 & $6.1-8.8$ & \\
\hline $45-64$ & 11534 & 2194 & 19.4 & $18.5-20.4$ & \\
\hline$\geq 65$ & 7186 & 1664 & 23.0 & $21.9-24.2$ & \\
\hline Race & & & & & $<0.0001$ \\
\hline White & 15834 & 2819 & 18.4 & $17.7-19.2$ & \\
\hline $\mathrm{AA}$ & 5269 & 800 & 23.6 & $21.8-25.3$ & \\
\hline Asian & 676 & 129 & 17.9 & $14.5-21.3$ & \\
\hline Other & 1732 & 292 & 14.9 & $12.9-17.0$ & \\
\hline Marital status & & & & & $<0.0001$ \\
\hline Married & 9542 & 2205 & 19.7 & $18.2-22.3$ & \\
\hline Divorced & 11969 & 1447 & 18.2 & $15.6-17.4$ & \\
\hline Single & 11969 & 385 & 13.4 & $11.9-14.9$ & \\
\hline Income, USD & & & & & $<0.0001$ \\
\hline $0-34999$ & 8443 & 1431 & 15.9 & $15.0-16.9$ & \\
\hline $35000-74999$ & 6142 & 1198 & 19.5 & $18.3-20.6$ & \\
\hline$\geq 75000$ & 5520 & 1141 & 20.7 & $19.4-22.1$ & \\
\hline Cancer history & & & & & $<0.0001$ \\
\hline No & 18691 & 3285 & 17.6 & $16.9-18.3$ & \\
\hline Yes & 2807 & 753 & 26.4 & $24.4-28.4$ & \\
\hline \multicolumn{6}{|l|}{ Alcohol use } \\
\hline Never & 4673 & 776 & 16.3 & $14.8-17.7$ & 0.0009 \\
\hline Past & 4343 & 888 & 20.3 & $18.6-21.8$ & \\
\hline Moderate & 11206 & 5151 & 19.3 & $18.3-20.3$ & \\
\hline Smoking status & & & & & $<0.0001$ \\
\hline Never & 11672 & 2063 & 17.6 & $16.6-18.5$ & \\
\hline Current & 3758 & 623 & 15.7 & $14.3-17.2$ & \\
\hline Past & 6043 & 1348 & 22.8 & $21.4-24.1$ & \\
\hline Depression & & & & & 0.0019 \\
\hline No & 17853 & 3244 & 18.3 & $17.6-18.9$ & \\
\hline Yes & 2652 & 570 & 21.4 & $19.4-23.4$ & \\
\hline Insomnia & & & & & 0.0001 \\
\hline No & 16577 & 3021 & 18.1 & $17.4-18.9$ & \\
\hline Yes & 4930 & 1018 & 20.9 & $19.6-22.3$ & \\
\hline Overall & 21511 & 4040 & 18.8 & $18.1-19.4$ & \\
\hline
\end{tabular}

a Abbreviations: AA, African American.

$\mathrm{b}$ P value is based on $\chi^{2}$ test.

c Data Source: CDC/NCHS, National Health Interview Survey, 2012. 
Owusu D et al.

\begin{tabular}{|c|c|c|c|c|c|c|}
\hline Variable & Crude OR & 95\%CI & PValue & Adjusted OR & 95\%CI & P Value \\
\hline \multicolumn{7}{|l|}{ Gender } \\
\hline Male & 1 & & & 1 & & \\
\hline Female & 0.73 & $0.66-0.81$ & $<0.0001$ & 0.73 & $0.66-0.82$ & $<0.0001$ \\
\hline \multicolumn{7}{|c|}{ Age group, y } \\
\hline $18-44$ & 1 & & & 1 & & \\
\hline $45-64$ & 2.99 & $2.42-3.70$ & $<0.0001$ & 2.91 & $2.35-3.62$ & $<0.0001$ \\
\hline$\geq 65$ & 3.71 & $2.98-4.63$ & $<0.0001$ & 3.76 & $2.99-4.74$ & $<0.0001$ \\
\hline \multicolumn{7}{|l|}{ Race } \\
\hline White & 1 & & & 1 & & \\
\hline AA & 1.35 & $1.21-1.52$ & $<0.0001$ & 1.74 & $1.53-1.98$ & $<0.0001$ \\
\hline Asian & 0.90 & $0.69-1.16$ & 0.406 & 1.05 & $0.80-1.37$ & 0.732 \\
\hline Other & 0.80 & $0.67-0.95$ & 0.01 & 1.07 & $0.89-1.28$ & 0.489 \\
\hline
\end{tabular}

\section{Marital status}

\begin{tabular}{|c|c|c|c|c|c|c|}
\hline Married & 1 & & & 1 & & \\
\hline Divorced & 0.91 & $0.83-0.99$ & 0.0456 & 0.91 & $0.82-1.02$ & 0.114 \\
\hline Single & 0.67 & $0.58-0.78$ & $<0.0001$ & 0.78 & $0.66-0.91$ & 0.002 \\
\hline \multicolumn{7}{|l|}{ Income, USD } \\
\hline $0-34999$ & 1 & & & 1 & & \\
\hline $35000-74999$ & 1.28 & $1.15-1.42$ & $<0.0001$ & 1.32 & $1.17-1.48$ & $<0.0001$ \\
\hline$\geq 75000$ & 1.34 & $1.19-1.50$ & $<0.0001$ & 1.50 & $1.31-1.73$ & $<0.0001$ \\
\hline \multicolumn{7}{|l|}{ Cancer history } \\
\hline No & 1 & & & 1 & & \\
\hline Yes & 1.71 & $1.52-1.94$ & $<0.0001$ & 1.51 & $1.32-1.73$ & $<0.0001$ \\
\hline \multicolumn{7}{|l|}{ Alcohol use } \\
\hline Never & 1 & & & 1 & & \\
\hline Past & 1.34 & $1.14-1.58$ & 0.0004 & 1.14 & $0.96-1.36$ & 0.142 \\
\hline Moderate & 1.25 & $1.11-1.42$ & 0.0004 & 1.16 & $1.01-1.34$ & 0.0361 \\
\hline \multicolumn{7}{|l|}{ Smoking status } \\
\hline Never & 1 & & & 1 & & \\
\hline Current & 0.90 & $0.78-1.03$ & 0.112 & 0.90 & $0.78-1.05$ & 0.176 \\
\hline Past & 1.40 & $1.26-1.56$ & $<0.0001$ & 1.17 & $1.04-1.32$ & 0.0119 \\
\hline \multicolumn{7}{|l|}{ Depress } \\
\hline No & 1 & & & 1 & & \\
\hline Yes & 1.23 & $1.08-1.40$ & 0.0025 & 1.37 & $1.18-1.58$ & $<0.0001$ \\
\hline \multicolumn{7}{|l|}{ Insomnia } \\
\hline No & 1 & & & 1 & & \\
\hline Yes & 1.18 & $1.07-1.31$ & 0.0014 & 1.18 & $1.06-1.32$ & 0.0041 \\
\hline
\end{tabular}

a Abbreviations: AA, African American; OR, Odds ratio; CI, Confidence interval.

b Data Source: CDC/NCHS, National Health Interview Survey, 2012.

\section{Discussion}

In the combined analysis, increasing age, high income, being male, depression, insomnia, past smoking, moderate alcohol drinking, and AA race were all associated with increased CRC screening. CRC screening prevalence was significantly reduced in the Single compared to the married or living with partner. In a stratified analysis by race groups, significant differences in CRC screening predictors were observed between Whites and AAs. There was a significant increase in CRC screening with increasing age, increasing income level, 
Owusu D et al.

and depression in both races. Similar to the combined analysis, females were less likely to screen for CRC in both Whites and AAs. Cancer history, marital status, and insomnia were associated with CRC screening in Whites but not in AAs. Past alcohol drinking increased screening in AAs but alcohol was not associated with screening in Whites. The relationship between age, gender, income level and CRC screening have been widely reported in the literature, and our findings are in line with those already reported $(9,12)$. However, in con- trast with findings in the literature $(9,12)$, our analysis found a significant increase in CRC screening among AAs compared to Whites. This increase may stem from perception of risk. Though our analysis cannot fully explain why CRC screening is higher in AAs than Whites, it is important to note that incidence of and mortality from CRC have been reported to be higher in AAs than all other racial/ethnic groups in the USA (20-24). Awareness of this statistics can trigger uptake of screening as has been shown previously (25).

Table 4. Multiple Logistic Regression Analysis for the Relationship between Potential Factors and CRC Screening by Race Status a,b

\begin{tabular}{|c|c|c|c|c|c|c|}
\hline Variable & Adjusted OR(White) & 95\%CI & PValue & Adjusted OR (AA) & 95\%CI & P Value \\
\hline \multicolumn{7}{|l|}{ Gender } \\
\hline Male & 1 & & & 1 & & \\
\hline Female & 0.71 & $0.62-0.80$ & $<0.0001$ & 0.77 & $0.61-0.97$ & 0.0251 \\
\hline \multicolumn{7}{|l|}{ Age group, y } \\
\hline $18-44$ & 1 & & & 1 & & \\
\hline $45-64$ & 2.66 & $2.08-3.98$ & $<0.0001$ & 3.62 & $2.15-6.09$ & $<0.0001$ \\
\hline$\geq 65$ & 3.20 & $2.47-4.14$ & $<0.0001$ & 4.96 & $2.84-8.64$ & $<0.0001$ \\
\hline \multicolumn{7}{|l|}{ Marital status } \\
\hline Married & 1 & & & 1 & & \\
\hline Divorced & 0.89 & $0.78-1.02$ & 0.0953 & 1.10 & $0.87-1.41$ & 0.429 \\
\hline Single & 0.75 & $0.61-0.92$ & 0.0067 & 0.93 & $0.68-1.26$ & 0.630 \\
\hline \multicolumn{7}{|l|}{ Income, USD } \\
\hline $0-34999$ & 1 & & & 1 & & \\
\hline $35000-74999$ & 1.32 & $1.14-1.51$ & 0.0001 & 1.46 & $1.15-1.86$ & 0.0021 \\
\hline$\geq 75000$ & 1.47 & $1.25-1.73$ & $<0.0001$ & 1.53 & $1.10-2.13$ & 0.0112 \\
\hline \multicolumn{7}{|l|}{ Cancer history } \\
\hline No & 1 & & & 1 & & \\
\hline Yes & 1.55 & $1.33-1.79$ & $<0.0001$ & 1.29 & $0.91-1.84$ & 0.157 \\
\hline \multicolumn{7}{|l|}{ Alcohol use } \\
\hline Never & 1 & & & 1 & & \\
\hline Past & 1.03 & $0.83-1.28$ & 0.772 & 1.49 & $1.06-2.09$ & 0.0218 \\
\hline Moderate & 1.13 & $0.95-1.34$ & 0.157 & 1.19 & $0.86-1.65$ & 0.301 \\
\hline \multicolumn{7}{|l|}{ Smoking status } \\
\hline Never & 1 & & & 1 & & \\
\hline Current & 0.94 & $0.79-1.11$ & 0.470 & 0.79 & $0.58-1.08$ & 0.146 \\
\hline Past & 1.17 & $1.02-1.34$ & 0.0302 & 1.23 & $0.91-1.65$ & 0.178 \\
\hline \multicolumn{7}{|l|}{ Depress } \\
\hline No & 1 & & & 1 & & \\
\hline Yes & 1.29 & $1.09-1.53$ & 0.0027 & 1.81 & $1.27-2.57$ & 0.001 \\
\hline \multicolumn{7}{|l|}{ Insomnia } \\
\hline No & 1 & & & 1 & & \\
\hline Yes & 1.17 & $1.03-1.34$ & 0.0185 & 0.93 & $0.69-1.24$ & 0.620 \\
\hline
\end{tabular}

a Abbreviations: AA, African American; OR, Odds ratio; CI, Confidence interval.

b Data Source: CDC/NCHS, National Health Interview Survey, 2012. 
Owusu D et al.

The observation that moderate alcohol drinking was associated with increase CRC screening is similar to previously reported influence of alcohol consumption on mammography (26). However, our results indicate that the relationship between moderate alcohol drinking and cancer screening may be race-dependent. When stratified by race, the observed 16\% increase in CRC screening in moderate alcohol consumption completely attenuated. It resulted in $47 \%$ significant increase in CRC screening among past alcohol users but only in AAs. More studies are needed to explain the racial difference. We have found no significant difference in CRC screening between current and never smokers in contrast to earlier finding that smoking reduces cancer screening $(27,28)$. In line with a previous report(10), we found past smoking to increase CRC screening in the combine analysis. Our stratified analysis indicated that past smoking increased screening in Whites only. Motivation to cease smoking may increase positive health behavior among past smokers. It suggests that campaigns to increase smoking cessation may also lead to improvement in healthy behaviors. Our findings on depression contrast most of the evidence reported earlier $(13-15,29)$. However, our analysis did not account for hospital visits. Number of outpatient visits has been found to mediate mental illness and health behavior (16). We are unable to attribute the observed influence of depression to physician visit based on our data, however, it is more plausible for depressed individuals to have increased contact with care providers (16) and the result may reflect the importance of health care provider contacts and screening uptake. This may also apply to those who reported symptoms of insomnia in the last 12 months. Increased contact with health care providers may increase uptake of health screening. Insomnia may affect up to $50 \%$ of patients with cancer and increases cancer symptom burden and impairs quality of life $(18,30-33)$. However, to the best of our knowledge, this study is the first to examine the relationship between insomnia and CRC screening uptake. We found that insomnia was positively associated with CRC screening and the associations showed race difference. Of significant important is the observed variation between Whites and AAs on the predictors examined. Though our data is limited to explain these differences, it suggests that race specific interventions may be important in improving uptake of CRC screening. However, further studies on these variations may be important to explain the difference. Our study is statistically powerful due to the large sample size. The use of probability sampling technique makes our sample representative of the population. Since information from participants was self-reported, our study may suffer from a recall bias as well as social desirability bias. However, recall bias is likely to be minimal since information collected was within one year. In conclusion, cancer history, smoking status, insomnia and alcohol intake status may influence CRC screening uptake differently between Whites and
AAs. To improve overall CRC screening uptake in the US, it is important to consider racial differences in predictors and tailor appropriate interventions to each racial/ ethnic group.

\section{Acknowledgements}

The authors would like to thank the CDC/NCHS for providing the data from the 2012 National Health Interview Survey.

\section{Authors' Contributions}

Daniel Owusu drafted the manuscript. Megan Quinn provided a substantive review of the manuscript. Ke Sheng Wang managed analyses and designed the study. All authors read and approved the manuscript.

\section{References}

1. Center for Disease Control and Prevention.. Colorectal (Colon) Cancer. USA: CDC; 2014. Available from: www.cdc.gov/cancer/ colorectal/statistics/index.htm.

2. Ries L, Melbert D, Krapcho M, Marios M. SEER cancer statistics review 1975-2004; based on November 2006 SEER data submission. Natl Cancer Inst. 2007. Available from: http:||seercancergov| csr/1975_2004/Bethesda.

3. National Cancer Institute.. SEER Stat Fact Sheets: Colon and Rectum. 2014. Available from: http://seer.cancer.gov/statfacts/html/ colorect.html.

4. Bretthauer M. Colorectal cancer screening. I Intern Med. 2011;270(2):87-98.

5. Espey DK, Wu XC, Swan J, Wiggins C, Jim MA, Ward E, et al. Annual report to the nation on the status of cancer, 1975-2004, featuring cancer in American Indians and Alaska Natives. Cancer. 2007;110(10):2119-52.

6. Walsh JM, Terdiman JP. Colorectal cancer screening: scientific review. JAMA. 2003;289(10):1288-96.

7. Atkin WS, Edwards R, Kralj-Hans I, Wooldrage K, Hart AR, Northover JM, et al. Once-only flexible sigmoidoscopy screening in prevention of colorectal cancer: a multicentre randomised controlled trial. Lancet. 2010;375(9726):1624-33.

8. Levin B, Lieberman DA, McFarland B, Smith RA, Brooks D, Andrews KS, et al. Screening and surveillance for the early detection of colorectal cancer and adenomatous polyps, 2008: a joint guideline from the American Cancer Society, the US Multi-Society Task Force on Colorectal Cancer, and the American College of Radiology. CA Cancer J Clin. 2008;58(3):130-60.

9. Seeff LC, Nadel MR, Klabunde CN, Thompson T, Shapiro JA, Vernon SW, et al. Patterns and predictors of colorectal cancer test use in the adult U.S. population. Cancer. 2004;100(10):2093-103.

10. Meissner HI, Breen N, Klabunde CN, Vernon SW. Patterns of colorectal cancer screening uptake among men and women in the United States. Cancer Epidemiol Biomarkers Prev. 2006;15(2):389-94.

11. McGregor SE, Hilsden RJ, Li FX, Bryant HE, Murray A. Low uptake of colorectal cancer screening $3 \mathrm{yr}$ after release of national recommendations for screening. Am J Gastroenterol. 2007;102(8):1727-35.

12. Beydoun HA, Beydoun MA. Predictors of colorectal cancer screening behaviors among average-risk older adults in the United States. Cancer Causes Control. 2008;19(4):339-59.

13. Holden AE, Ramirez AG, Gallion K. Depressive symptoms in Latina breast cancer survivors: a barrier to cancer screening. Health Psychol. 2014;33(3):242-8.

14. Ludman EJ, Ichikawa LE, Simon GE, Rohde P, Arterburn D, Operskalski BH, et al. Breast and cervical cancer screening specific effects of depression and obesity. Am J Prev Med. 2010;38(3):303-10. 
15. Kaida A, Colman I, Janssen PA. Recent Pap tests among Canadian women: is depression a barrier to cervical cancer screening? J Womens Health (Larchmt). 2008;17(7):1175-81.

16. Kodl MM, Powell AA, Noorbaloochi S, Grill JP, Bangerter AK, Partin MR. Mental health, frequency of healthcare visits, and colorectal cancer screening. Med Care. 2010;48(10):934-9.

17. Miles A, Rainbow S, von Wagner C. Cancer fatalism and poor selfrated health mediate the association between socioeconomic status and uptake of colorectal cancer screening in England. Cancer Epidemiol Biomarkers Prev. 2011;20(10):2132-40.

18. O'Donnell JF. Insomnia in cancer patients. Clin Cornerstone. 2004;6(1):S6-S14.

19. National Center for Health Statistics.. NHIS Survey Description 2012 National Health Interview Survey (NHIS) Public Use Data Release .Maryland: Centers for Disease Control and PreventionU.S. Department of Health and Human Services; 2013.

20. Chu KC, Tarone RE, Chow WH, Alexander GA. Colorectal cancer trends by race and anatomic subsites, 1975 to 1991. Arch Fam Med. 1995;4(10):849-56.

21. Cooper GS, Yuan Z, Rimm AA. Racial disparity in the incidence and case-fatality of colorectal cancer: analysis of 329 United States counties. Cancer Epidemiol Biomarkers Prev.1997;6(4):283-5.

22. Cress RD, Morris CR, Wolfe BM. Cancer of the colon and rectum in California: trends in incidence by race/ethnicity, stage, and subsite. Prev Med. 2000;31(4):447-53.

23. Ward E, Jemal A, Cokkinides V, Singh GK, Cardinez C, Ghafoor A, et al. Cancer disparities by race/ethnicity and socioeconomic status. CA Cancer J Clin. 2004;54(2):78-93.

24. Irby K, Anderson WF, Henson DE, Devesa SS. Emerging and widening colorectal carcinoma disparities between Blacks and Whites in the United States (1975-2002). Cancer Epidemiol Bio- markers Prev. 2006;15(4):792-7.

25. Cram P, Fendrick AM, Inadomi J, Cowen ME, Carpenter D, Vijan S The impact of a celebrity promotional campaign on the use of colon cancer screening: the Katie Couric effect. Arch Intern Med. 2003;163(13):1601-5.

26. Fredman L, Sexton M, Cui Y, Althuis M, Wehren L, Hornbeck P, et al. Cigarette smoking, alcohol consumption, and screening mammography among women ages 50 and older. Prev Med. 1999;28(4):407-17.

27. Selvin E, Brett KM. Breast and cervical cancer screening: sociodemographic predictors among White, Black, and Hispanic women. Am J Public Health. 2003;93(4):618-23.

28. Rakowski W, Clark MA, Ehrich B. Smoking and cancer screening for women ages 42-75: associations in the 1990-1994 National Health Interview Surveys. Prev Med. 1999;29(6 Pt 1):487-95.

29. Myong JP, Shin JY, Kim SJ. Factors associated with participation in colorectal cancer screening in Korea: the Fourth Korean National Health and Nutrition Examination Survey (KNHANES IV). Int J Colorectal Dis. 2012;27(8):1061-9.

30. Lis CG, Gupta D, Grutsch JF. The relationship between insomnia and patient satisfaction with quality of life in cancer. Support Care Cancer. 2008;16(3):261-6.

31. Howell D, Oliver TK, Keller-Olaman S, Davidson J, Garland S, Samuels C, et al. A Pan-Canadian practice guideline: prevention, screening, assessment, and treatment of sleep disturbances in adults with cancer. Support Care Cancer. 2013;21(10):2695-706.

32. Theobald DE. Cancer pain, fatigue, distress, and insomnia in cancer patients. Clin Cornerstone. 2004;6(1):15-21.

33. Irwin MR. Depression and insomnia in cancer: prevalence, risk factors, and effects on cancer outcomes. Curr Psychiatry Rep. 2013;15(11):404. 